\title{
The formation of the cutting tool microgeometry by pulsed laser ablation
}

\author{
Sergey V. Fedorov ${ }^{1, *}$, Evgeny A. Ostrikov ${ }^{1}$, Enver S. Mustafaev ${ }^{1}$, and Khaled Hamdy ${ }^{2}$ \\ 1 MSTU "STANKIN", Vadkovskiy Lane, 3a, Moscow 127055, Russia \\ 2 Minia University, El-Minia-Cairo-Aswan Road, El-Minia 61519, Egypt
}

Received: 16 October 2018 / Accepted: 12 February 2019

\begin{abstract}
Laser ablation is considered as an alternative to other methods that allow precise processing of various tool materials and work with both the base material and thin films of wear-resistant coatings. This article presents an investigation of the possibility of setting the microgeometry of the surface of cutting tool made of high-speed steel $\mathrm{M} 2$ and hard alloy $\mathrm{WCCO}_{3}$ using ablation with nanosecond infrared marking Nd:YVO4 laser. Dependencies of the width and depth of the resulting tracks on the specified laser power are obtained. It was revealed that their depth depends on a set of several specified factors: power, scanning speed, pulse frequency rate, and a number of passes. The modes with a radiation power of up to $70 \%$ are of interest for the treatment of the tool surface using a laser because they have a more predictable profile and more efficient energy distribution. The most uniform and smooth surface were obtained after laser treatment with the following parameters: power $60 \%$, frequency $10 \mathrm{kHz}$, scanning speed $200 \mathrm{~mm} / \mathrm{s}$ irrespective of the material being processed. The greater flexibility of the coating material for laser processing was observed. The depth of tracks on the coated (TiAl)N samples is larger than on the uncoated samples. The possibility to obtain a chamfer with the specified width and angle parameters by laser processing based on the obtained dependencies is demonstrated.
\end{abstract}

Keywords: Laser ablation / nanosecond marking Nd:YVO4 laser / high-speed steel / hard alloy / microgeometry / cutting edge

\section{Introduction}

The development of modern machine-building production cannot be imagined without the introduction of innovative technologies that highly increase the productivity of cutting action. Some of these technologies are directly related to the improvement of modern high-performance cutting tools, which have a significant impact on the efficiency and reliability of the production process $[1,2]$.

Most modern cutting tools are supplied with a certain wear-resistant coating. Such processing has long been an integral part of tool production. Moreover, although a little more than 40 years ago the industry was satisfied with the simplest, from a modern point of view, monolayer coatings, such as nitrides and carbo-nitrides of titanium, chromium, molybdenum, zirconium [3], now complex multicomponent gradient, multilayer, nanostructured compositions are widely used. Able to provide the high strength of interlayer adhesion and rational values of hardness and viscosity, they have a low coefficient of friction and high resistance to

\footnotetext{
* e-mail: sv.fedorov@icloud.com
}

abrasive wear and offer high opposition to diffusion and thermal flows $[4,5]$. The use of automated systems allows the application of complex multilayer composite nanometric structures of different composition and functional purposes $[6,7]$.

Nevertheless, the production site for coatings cannot do without other process equipment, among which will certainly be the sets for the preparation of the tool both before and after coating. The process involves the influence on the microtopography of the tool surface, the integrity and cleanliness of its surface, and, most importantly, the state of the cutting edge, which has a significant impact on the thermomechanical characteristics of the cutting process.

Among the methods of such exposure, are well known, for example, microabrasive [8] and water jet [9] treatments. It is promising to use this technology to clean the surface of the solid oxide layers and an excess of cobalt binder, formed in the grinding operation of a hard alloy tool [10]. The results showed that the combination of both methods is effective, but the possible contamination of the surface with abrasive particles can still cause significant problems in the subsequent coating of parts and tools $[11,12]$. 
Similar results were obtained using chemical and thermal methods of pretreatment. In this case, plasma nitriding [13-15], including ion-assisted nitriding [16,17], and surface alloying $[18,19]$ are often used. It was found that such treatment improves the physicochemical characteristics of the substrate and its chemical affinity with the deposited material, as well as eliminates the sharp interface of separation between a relatively soft substrate and a hard coating.

Laser processing of the surface and edges of the cutting tool is one of the promising methods of processing. Although the service life of the laser-machined tool is slightly different from a tool treated with abrasive [20,21], the advantages of this processing method include high reproducibility, accuracy, the ability to process complex surfaces, local impact on the surface, and the ability to process superhard materials, for which traditional mechanical methods are practically unsuitable.

In addition to cutting edge treatment before coating, it is possible to adjust the cutting edge after coating or even to remove it locally [22]. It is also possible to form a surface structure that improves chip formation. After applying the wear-resistant coating, the surface defects, drops, and irregularities are formed, and the radius of the edge increases. In this case, there can be made a further laser treatment to reduce the radius of rounding. The peculiarity is that a part of the coating on the back or front surface is removed and a zone with low wear resistance is formed. In this case, one can observe the effect of self-sharpening of the cutting tool $[23,24]$. The results of the research showed that the use of this method of coating reduces the forces that occur during the cutting process, due to the preservation of a constant value of the edge radius for a long time.

There is also a possibility of laser treatment of the tool surface to remove wear-resistant coatings to further restore the cutting properties of the worn tool $[25,26]$. The process is relevant for the processing of cutting edges, which are hard to regrind, for example, auxiliary cutting edges on spiral drills or end mills [27].

There is some scientific works devoted to the study of the dependence of roughness [28], surface structure, and residual stresses [29] on the parameters of laser processing, as well as comparison with other methods of processing. The adhesion of the coating to the substrate was increased after preliminary laser exposure [30,31]. However, it should be taken into account that too high specific energy of laser irradiation leads to a significant change in the structure of the processed material.

The range of products manufactured by companies specializing in the production of tools is extremely high. However, the producer is often faced with the need to manufacture their own special tools, especially in the processing of complex form and this, as a rule, is a single or, in rare cases, small-scale production. In the presence of a modern grinding machine, such a special tool with a given microgeometry is possible to produce, but it will be more expensive than using the proposed much cheaper laser technology and equipment.

The novelty of the present work is the study of the operating modes of laser equipment for determining the capabilities of selective microprocessing of the tool surface.
The research tasks of the study are to identify the influence of laser processing factors on the width and depth of the resulting tracks and to determine the rational processing modes for specifying the microgeometry of the cutting edge. Some types of materials, high-speed steel and hard alloy with and without coatings, were chosen to assess the difference in the nature of laser ablation effects on different materials.

\section{Materials and methods}

\subsection{Objects of research}

The grinding plates of high-speed steel $\mathrm{M} 2\left(\mathrm{FeC}_{0.85}\right.$ $\left.\mathrm{W}_{6} \mathrm{Mo}_{5} \mathrm{Cr}_{4} \mathrm{~V}_{2} \mathrm{Co}_{0.5}\right)$ and hard alloy based on tungsten carbide with a cobalt binder content of $3 \%$ were selected for the research. The preparation of the cutting edge for a carbide tool without a coating and with a multilayer coating (TiAl)N applied on a Platit $\pi 80$ unit (Platit AG, Selzach, Switzerland) was carried out. The thickness of the coating was $4-6 \mu \mathrm{m}$. Measuring the radius of rounding of the cutting edge was carried out on an optical profilometer MicroCAD premium + (GFM, Berlin, Germany). The surface microstructure was studied using an optical microscope AxioCam (Carl Zeiss, Jena, Germany) equipped with long-focus lenses of the Epiplan-Neofluar series and a scanning electron microscope VEGA 3 LMH (TESCAN, Brno, Czech Republic).

\subsection{Laser processing}

The purpose of the research was to study the effect of laser processing on the geometry of the cutting tool. The task was to search for the modes when cracking and solid fusion of individual areas was not occurring in the treatment zone, and the possibility of chipping and cleavage of the cutting edge segments was excluded.

The removal mechanisms for metals and metal-like materials, which include normal boiling, normal evaporation, and explosive effervescence (phase explosion), mainly depend on the intensity of laser radiation and its duration [32]. Lasers are divided into four groups: micro-, nano-, pico-, and femtosecond. The normal boiling mode is typical for laser radiation with long pulses (hundreds of microseconds and higher) at moderate power. Under this influence, a quasi-stationary jet stream of evaporation products is formed above the surface of the irradiated material. As the intensity of the laser radiation increases, a transition from normal to explosive boiling [33] occurs. In order to evaporate the material of the workpiece or tool, the intensity of the laser beam should exceed the value of the beginning of sublimation. The intensity of the laser beam also depends on the frequency of the pulses, which determines the power of the pulse peak [34].

The utmost influence on the formation of the cutting edge has a degree of overlapping of successive pulses. The accuracy of the processing depends on the number of layers removed, which are necessary to produce the required radius of rounding of the cutting edge. In this case, as a rule, the removal of several layers is required, and the more the number of the removed layers, the lower the accuracy of 
Table 1. Technical characteristics of the system U-15.

\begin{tabular}{ll}
\hline Radiation source & Built-in, diode-pumped \\
\hline & Nd:YVO4 \\
Wavelength & $1064 \mathrm{~nm}$ \\
The output power of radiation & $15 \mathrm{~W}$ \\
Peak pulse power & $120 \mathrm{~kW}$ \\
Pulse duration & $\sim 10 \mathrm{~ns}, 10 \mathrm{kHz}$ \\
The diameter of the beam spot & $\sim 50 \mu \mathrm{m}(163 \mathrm{~mm}$ \\
in the focus point & F-Theta lens $)$ \\
Marking field & $100 \times 100 \mathrm{~mm}(163 \mathrm{~mm}$ \\
& F-Theta lens $)$ \\
\hline
\end{tabular}

manufacturing. However, laser processing still provides sufficient processing accuracy to obtain the radius or chamfer of the required value.

The tests were carried out on the laser marking system U-15 (RMI Laser, Lafayette, USA). It is the Nd: YVO4, a solid-state laser marker with diode pumping. Its technical characteristics are given in Table 1 . The laser allows setting a wide range of radiation power, pulse frequency, scan speed, and the number of passes.

Since in q-switched pulsed lasers the high pulse repetition rate can lead to a decrease in the peak pulse energy $\left(E_{\text {pulse }}\right)$, it makes sense to estimate approximately the maximum pulse frequency $(f)$ above which the peak pulse power $\left(P_{\text {peak }}\right)$ will drop (Fig. 1$)$.

As is known, peak power is determined by the following expression:

$$
P_{\text {peak }}=\frac{E_{\text {pulse }}}{t_{\text {pulse }}},
$$

where $E_{\text {pulse }}$ is the pulse energy $(\mathrm{J})$ and $t_{\text {pulse }}$ is the duration of the pulse (s).

The pulse energy, in turn, can be defined as

$$
E_{\text {pulse }}=\frac{P_{\mathrm{avg}}}{f},
$$

where $P_{\text {avg }}$ is the output power of the radiation (W) and $f$ is the pulse frequency $(\mathrm{Hz})$.

According to the passport characteristics of the laser marking system U-15 (Tab. 1), the average laser power is $P_{\text {avg }}=15 \mathrm{~W}$, and the maximum peak power is $P_{\text {peak }}=$ $120 \mathrm{~kW}$. Substituting these values in the given formulas and performing the transformation, we can estimate the maximum frequency above which the laser can have a power drop:

$$
f=\frac{P_{\text {avg }}}{P_{\text {peak }} \cdot t_{\text {pulse }}}=12.5 \mathrm{kHz}
$$

Considering also that the change of pulse repetition frequency affects both the peak power of the pulse and the intensity of treatment, which can lead to a change in the ablation threshold, this work did not consider the

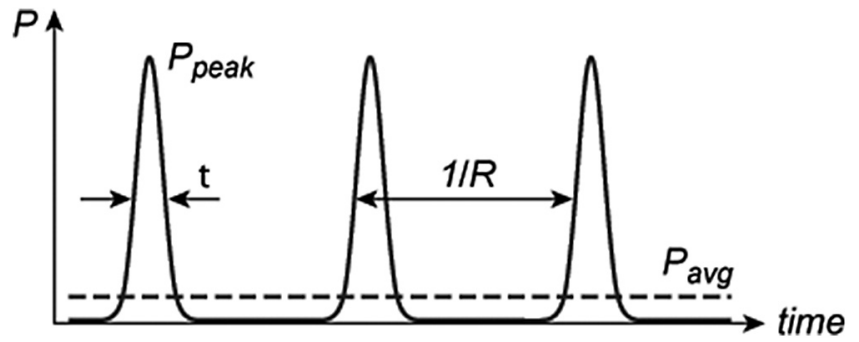

Fig. 1. Laser pumping diagram.

integrated effect of pulse repetition frequency on the nature of surface treatment. It was decided to limit the frequency to $10 \mathrm{kHz}$.

Since initially the laser marking system U-15 was not able to change the positioning of the treated surface, it was modernized. A table that allows the object to be moved along three axes and a microscope with a video camera that facilitates aiming were set up for the installation.

\section{Results}

\subsection{Investigation of laser-operating modes}

The first stage of experimental research was the visual definition of defects on the surface of the tool when laser radiation was exposed to it under various parameters. The investigations were carried out on samples of high-speed steel M2 and hard alloy with (TiAl)N coating and without it. The radiation power was varied from 10 to $100 \%$, the pulse frequency was $10 \mathrm{kHz}$, the scanning speed was varied from 210 to $1000 \mathrm{~mm} / \mathrm{s}$, and the number of passes was up to 100.

The depth of ablation with the number of passes less than 20 is difficult to determine due to a too small value that is close to the size of irregularities on the surface of the treated object.

As shown by experiments, at power values above $70 \%$, the transverse energy distribution in the pulse differs significantly from the Gaussian distribution and has a more complex profile (Fig. 2).

Examples of characteristic images of tracks are presented in Figure 3. The images clearly show the traces of the pulse overlap and how, depending on the step between the pulses, micronutrients are formed, and, consequently, forms the roughness of the treated surface. There are also noticeable changes in the pulse energy distribution over the area depending on the specified power.

The obtained profiles, along which the ablation depth was determined, are shown in Figures $4 \mathrm{a}$ and $4 \mathrm{~b}$. It can be seen that at the average modes the material removal profile has a distribution close to Gaussian, almost the same as the transverse distribution of laser intensity. There are welldefined nodules along the edges of paths, which are formed by laser action, and they are more typical for samples with the wear-resistant coating.

At high laser power levels, a significant change in the shape of the laser spot and an increase in its area is observed and, as a result, there is an increase in the width of the 


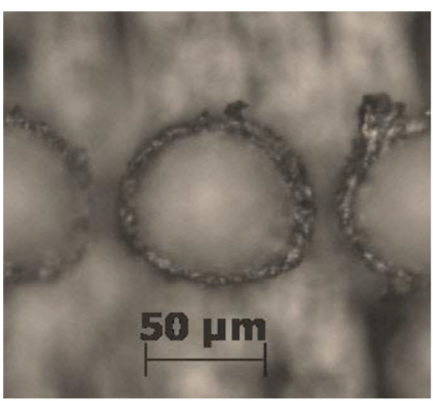

(a)

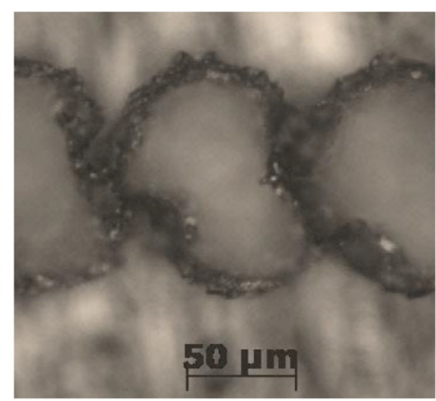

(b)

Fig. 2. Craters after laser processing with a scanning speed of $1000 \mathrm{~mm} / \mathrm{s}$ and a frequency of $10 \mathrm{kHz}$ : (a) with a power of $60 \%$ from the nominal value; (b) with a power of $100 \%$ from the nominal value.

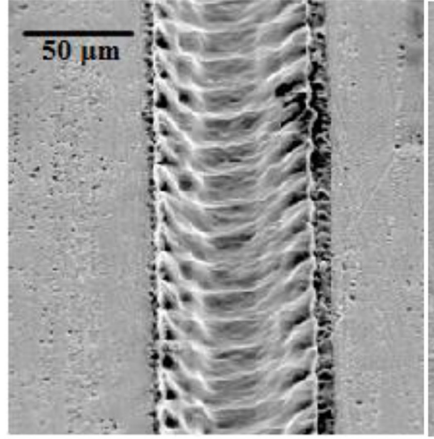

(a)

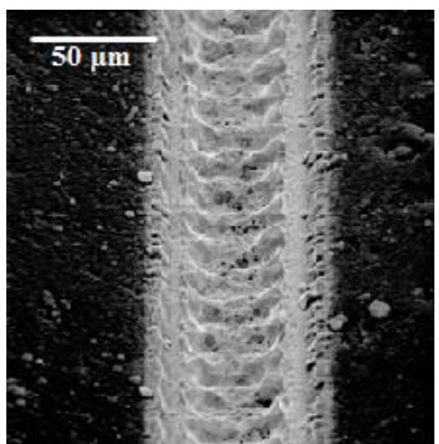

(c)

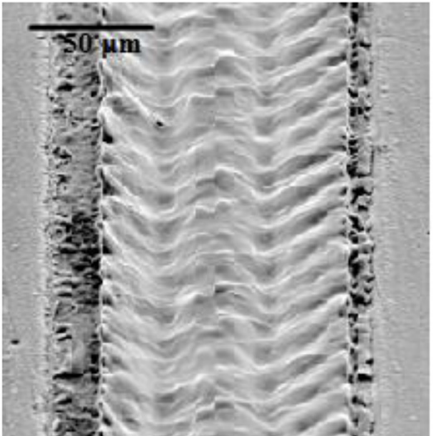

(b)

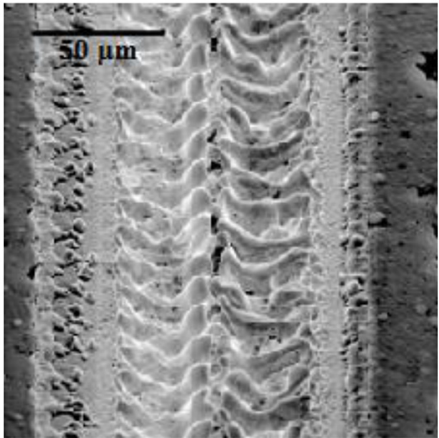

(d)

Fig. 3. Structure of tracks on a sample after laser treatment with a frequency of $10 \mathrm{kHz}$, a scanning speed of $200 \mathrm{~mm} / \mathrm{s}$, and 40 passes: (a) high-speed steel M2 with a power of $60 \%$; (b) highspeed steel M2 with a power of $100 \%$; (c) hard alloy coated with (TiAl)N with a power of $60 \%$; (d) hard alloy coated with (TiAl)N with a power of $100 \%$.

tracks and a decrease in the processing efficiency, expressed in a decrease in ablation depth. In the middle of the tracks appears a projection associated with the feature of the energy distribution in the pulse. The characteristic profiles for steel and hard alloy are shown in (Figs. 4c and 4d).

Thus, for treatment of the tool surface using a laser, modes with a radiation power of up to $70 \%$ are of interest

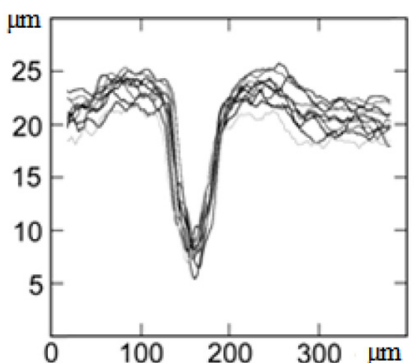

(a)

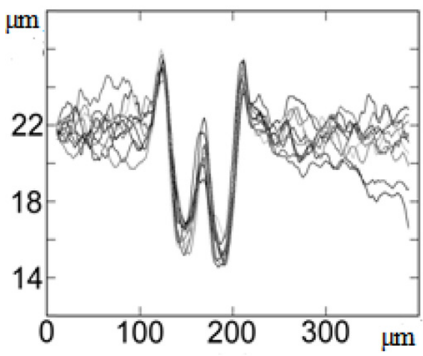

(c)

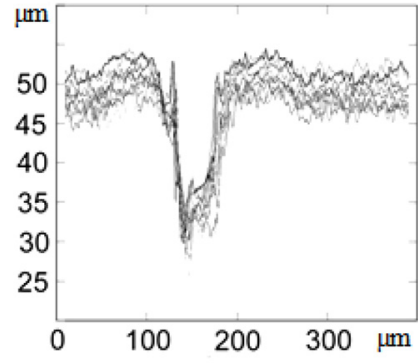

(b)

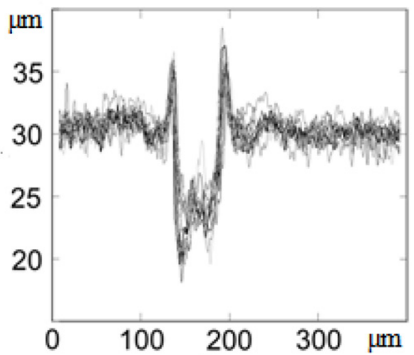

(d)
Fig. 4. Cross section profiles of the tracks with a scanning speed of $400 \mathrm{~mm} / \mathrm{s}$ and a pulse frequency of $10 \mathrm{kHz}$ : (a) high-speed steel M2 samples coated with (TiAl)N with a power of $60 \%$ and 40 passes; (b) hard alloy samples coated with $(\mathrm{TiAl}) \mathrm{N}$ with a power of $60 \%$ and 100 passes; (c) high-speed steel M2 samples with two lows, a power of $90 \%$, and 40 passes; (d) hard alloy samples with two lows, a power of $80 \%$, and 100 passes.

because they have a more predictable profile and more efficient energy distribution.

\subsection{Characteristics of ablation}

In order to form the cutting edge and microgeometry of the tool, it is first necessary to evaluate the effect of laser processing on the geometric parameters of the resulting tracks, namely, to reveal the relationship between the width and depth of the tracks and the specified factors of the laser operation.

The nanosecond laser creates microgeometry on the tool surface by removing the material by laser ablation, which is characterized by a certain ablation threshold for each material [35]. When the threshold is exceeded, explosive evaporation of the material and the formation of a crater take place.

For a laser beam with Gaussian energy distribution, the radiation intensity has a maximum value at the center of the laser beam and decreases exponentially depending on the distance from the center.

$$
F(x)=F_{c} \cdot e^{-\left(\frac{2 \cdot x^{2}}{\omega_{0}^{2}}\right)},
$$

where $F_{c}$ is the intensity of the laser at the center of the laser beam $\left(\mathrm{J} / \mathrm{cm}^{2}\right), \omega_{0}$ is the radius of the beam $(\mathrm{mm})$ at which the intensity falls by $1 / \mathrm{e}^{2}$ times, and $x$ is the distance from the center of the laser beam ( $\mathrm{mm})$. 


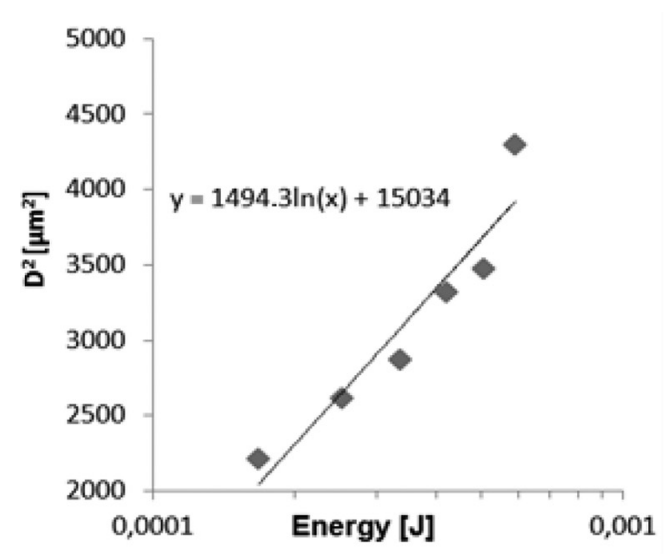

(a)

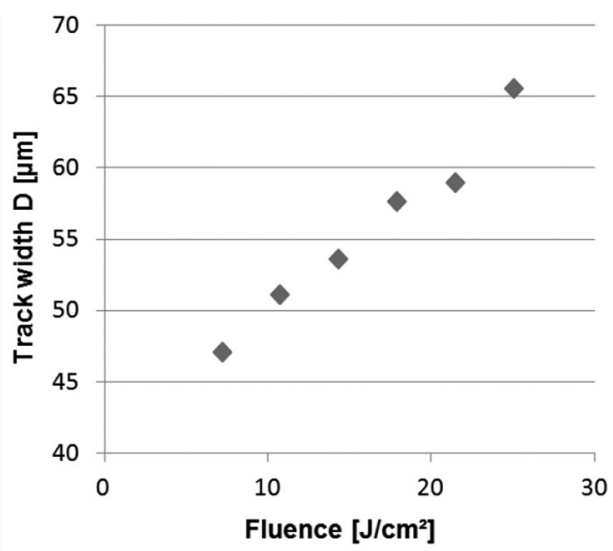

(b)

Fig. 5. Dependencies: (a) dependence of the area of the crater $D^{2}$ on the given energy for the determination of the radius $\omega$; (b) dependence of the track width $D$ on the fluence.

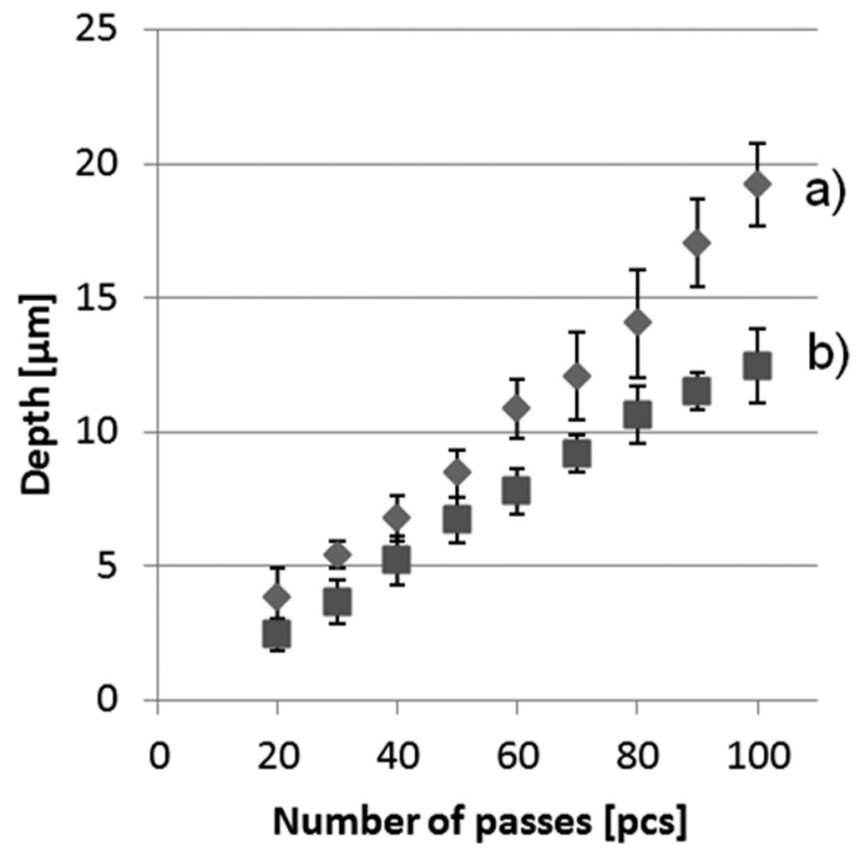

Fig. 6. Dependence of the depth of the obtained tracks on the number of laser passes: (a) high-speed steel M2; (b) hard alloy.

If the value of the radius $r$ of the resulting crater is inserted into equation (4), we obtain the threshold value of the fluence $F_{\text {th }}$ at which the ablation begins to occur. Expressing $r$ from the formula and replacing it with the diameter of the crater $D(\mu \mathrm{m})$, we obtain the dependence of the width of the track on fluence:

$$
D^{2}=2 \omega^{2} \ln \left(\frac{F_{c}}{F_{\mathrm{th}}}\right)
$$

We cannot only acquire the dependence of the track width on the fluence but also calculate $\omega$ to find the fluence values for a particular laser having the obtained expression.
The relationship between the pulse energy and the fluence is linear. At first, we construct the dependence of the area of the craters on the given energy of the pulses and determine $\omega$ on the slope of this dependence (Fig. 5a). Thereafter, it will be possible to determine the dependence of the track width on the fluence (Fig. 5b).

Furthermore, before considering the effect of laser energy on the depth of the crater, we consider the effect of the number of laser passes on the depth of the crater (Fig. 6). It can be seen that on an interval of up to 100 passes, this dependence can be considered linear and can be calculated by the depth of ablation per pulse. The dependence of ablation depth on a given fluence can be expressed as follows [36]:

$$
h=\frac{1}{\alpha} \ln \left(\frac{F_{0}}{F_{\text {th }}}\right),
$$

where $h$ is the ablation depth $(\mu \mathrm{m})$ and $\alpha$ is the optical permeability of the material.

It is possible to determine the depth of the tracks depending on the given fluence for steel M2 and hard alloy (Fig. 7).

The research has shown that the depth of tracks is affected not only by the radiation power and the number of passes but also by the interval between the pulses. At a smaller interval, an increase in the depth of tracks is observed, which may be associated with a large amount of energy per area unit due to overlapping of the areas of adjoining pulses. However, the laser radiation power will also affect the effective overlap area of the pulses.

The track width increases with increasing power, as the diameter of the resulting craters increases with increasing laser radiation power (Fig. 8). It means that a different ratio of scan speed to pulse frequency can affect the nature and intensity of the laser treatment and, as a result, the resulting microgeometry of the treated surface.

It has been noticed that for the same processing factors, the depth of tracks on the (TiAl)N-coated samples is larger than on the uncoated samples (Tab. 2). It suggests that the 


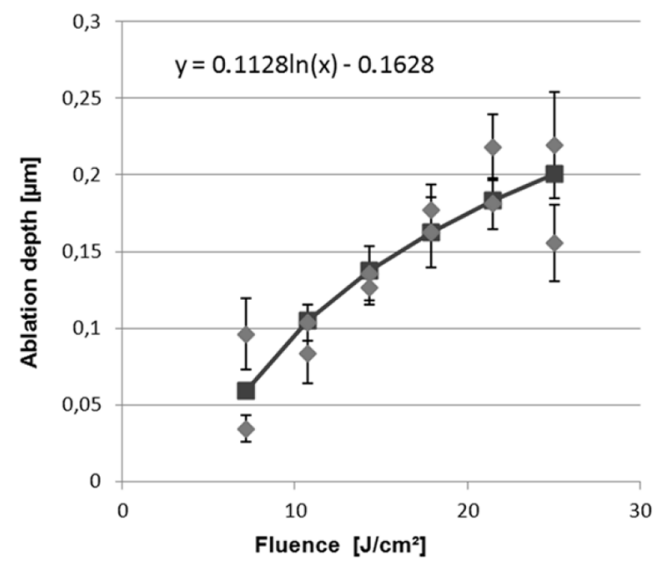

(a)

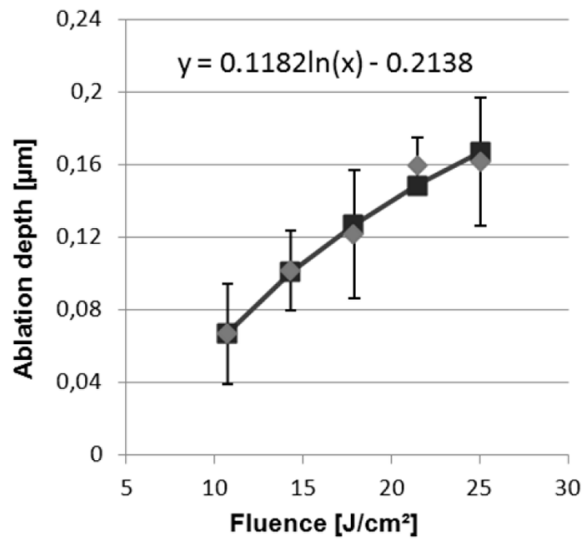

(b)

Fig. 7. Dependencies of the ablation depth on the specific energy of laser radiation: (a) high-speed steel M2; (b) hard alloy.

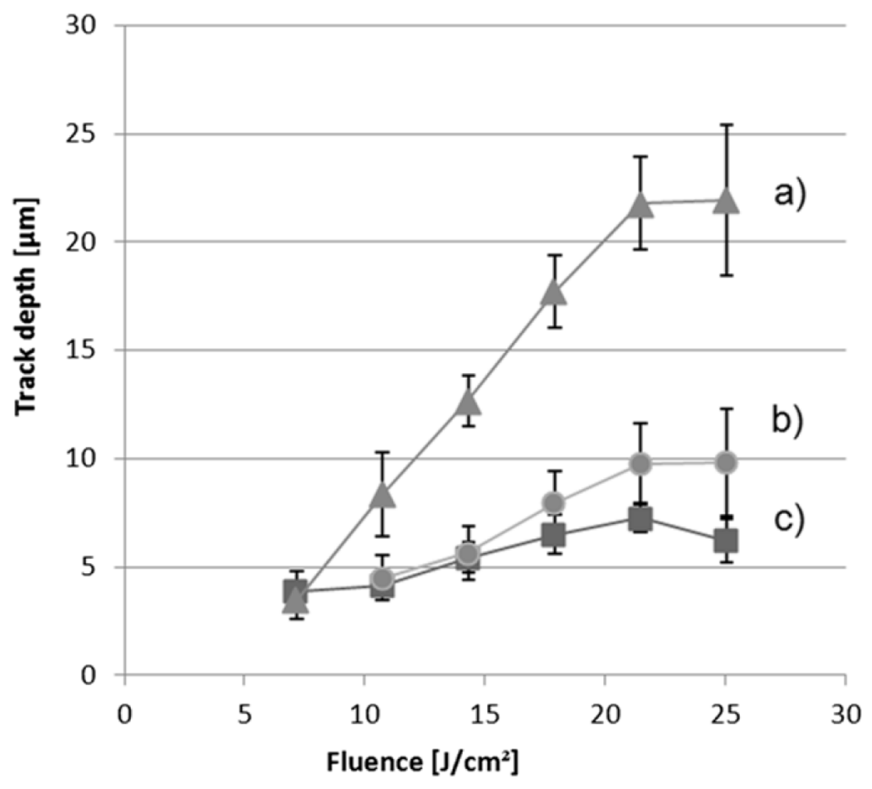

Fig. 8. Dependence of the depth of the resulting tracks on the fluence for high-speed steel M2: (a) with a scanning speed of $400 \mathrm{~mm} / \mathrm{s}$ and 100 passes; (b) with a scanning speed of $200 \mathrm{~mm} / \mathrm{s}$ and 40 passes.

coating material is more malleable for laser treatment and has a lower ablation threshold, which allows the laser to process the coating itself, minimizing the effect of the laser on the substrate.

\section{Discussion}

A significant part of the failure of the cutting tool is caused by damage to the cutting edge, which in most cases is caused by exceeding the allowable tensile stresses on the working surfaces $[37,38]$. Rounding of the cutting edge allows changing the direction of the resulting cutting force, which gives the possibility to reduce the tensile stresses on
Table 2. The depth of tracks on a hard alloy with laser processing parameters: a laser power of $60 \%$, an interval of $20 \mu \mathrm{m}, 100$ of passes, and a pulse frequency of $10 \mathrm{kHz}$.

\begin{tabular}{lll}
\hline Track number & $\begin{array}{l}\text { Track depth } \\
\text { without coating }(\mu \mathrm{m})\end{array}$ & $\begin{array}{l}\text { Track depth } \\
\text { with coating }(\mu \mathrm{m})\end{array}$ \\
\hline 1 & 11.96 & 13.80 \\
2 & 12.48 & 13.79 \\
3 & 12.04 & 13.95 \\
4 & 12.83 & 14.62 \\
\hline
\end{tabular}

the front surface significantly. On the other hand, an excessive increase in the radius of rounding will increase force and cutting temperature [39].

Ordinary shapes of the base cutting edge are rounded, sharp, and chamfered. There are also cutting edge shapes, which are a combination of these three basic shapes. The most prevalent cutting tool with a rounded edge is obtained by finishing, semifinishing, and microprocessing, chamfered by lathe turning of workpieces of solid material and intermittent cutting [40,41]. Parameters for the characterization of the chamfered cutting edge are the chamfer length and its angle. The shape of the rounded cutting edge is complex, and the rounding radius is the most commonly used parameter for its characteristic. However, due to emerging problems in measuring of asymmetric edges, the form-factor method is used [42], which allows estimating the average roundness of the cutting edge, the orientation of the rounding, and its sharpness. The tool wear shows dependence on the parameter of roundness $K$ [43]. Thus, when the roundness is displaced to the front surface, its wear is observed until a negative front angle is reached. When changing the rounded shape of the edge to the value $K<1$, the back surface wears out due to increased friction between the back surface of the tool and the surface of the processed material.

The numerical evaluation of the influence of geometric parameters of the cutting edge and the roughness of the 


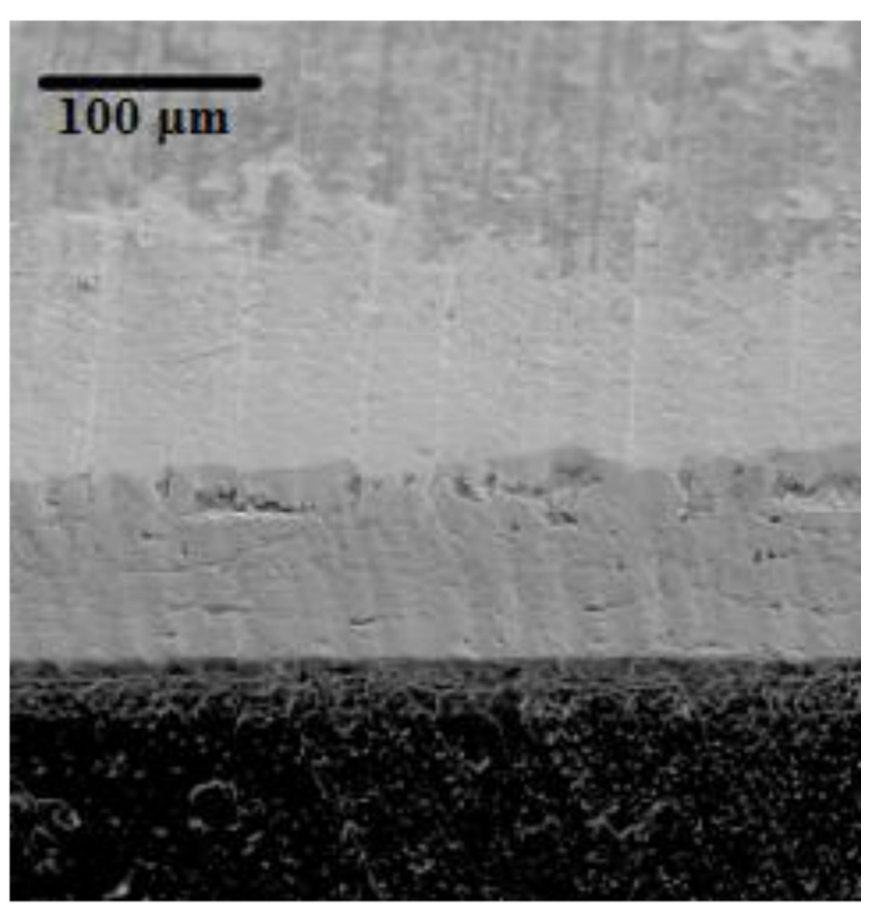

Fig. 9. Edge with a chamfer on the cutting plate of high-speed steel M2, obtained by laser ablation with parameters: an intensity of $21.5 \mathrm{~J} / \mathrm{cm}^{2}$, a frequency of $10 \mathrm{kHz}$, a scanning speed of $200 \mathrm{~mm} / \mathrm{s}$, and a number of passes of 300 .

working surfaces on cutting forces and stress distribution in the cutting tool edge zone showed a more significant effect on the force in the feed direction than the force in the cutting direction $[44,45]$.

Precision cutting tools with a sharp edge (rounding radius $<5 \mu \mathrm{m}$ ) facilitate cutting compared to a tool with a large radius of the edge. At the same time, the stresses in the tool would have to decrease with decreasing of the radius. However, it does not happen, because a sharp tool has a higher stress concentration in the cutting edge area than a less sharp cutting tool. It is a possible cause of edge chipping. Therefore, to minimize breakage, its shape should be prepared in such a way that a certain balance between the amount of the stresses and cutting forces is achieved.

By the conducted researches, in which were determined the parameters of the stable operation of the laser and the dependence of the ablation depth from the factors of laser radiation, the required values for the formation of the cutting edge geometry in the form of a chamfer were selected. The required geometry of the cutting edges was selected $a_{c}=20^{\circ}$ (chamfer angle), $w_{c}=0.1 \mathrm{~mm}$ (chamfer length), and $r_{\mathrm{h}}=0.01 \mathrm{~mm}$ by the geometry proposed in reference [46] by mathematical modeling. For a tool with such a cutting edge, a minimum cutting temperature on the front and back surfaces would be observed, as well as relatively low effective internal stresses of up to $2800 \mathrm{MPa}$.

The values of the factors of laser operation for the production of a similar cutting edge on the cutting plate made of steel M2 coated in (TiAl) N were determined: a

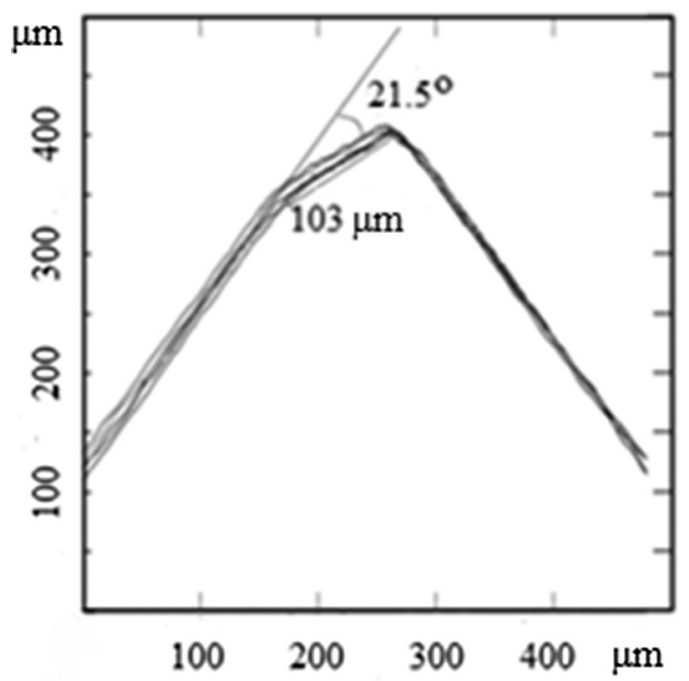

Fig. 10. Light sections of the cutting edge with a chamfer on the cutting plate of high-speed steel M2, obtained by laser ablation with parameters: an intensity of $21.5 \mathrm{~J} / \mathrm{cm}^{2}$, a frequency of $10 \mathrm{kHz}$, a scanning speed of $200 \mathrm{~mm} / \mathrm{s}$, and a number of passes of 300 .

laser radiation intensity of $21.5 \mathrm{~J} / \mathrm{cm}^{2}$, a frequency of $10 \mathrm{kHz}$, a scanning speed of $200 \mathrm{~mm} / \mathrm{s}$, and a number of passes of 300 . The processing time was about $15 \mathrm{~s}$.

SEM image of the front and back surfaces of the cutting insert is shown in Figure 9. The light section of the cutting edge is shown in Figure 10. The radius of rounding of the cutting edge was $16 \mu \mathrm{m}$.

Similar or any other microgeometry of the area adjacent to the cutting edge is not difficult to repeat on the cutting plates made of hard alloy. In this case, it takes up to $40 \mathrm{~s}$ to process one cutting edge.

The tool with a given microgeometry of the cutting edge showed itself well when turning at intensive abrasive wear with large fluctuations in the values of the workpiece hardness. Such conditions arise, for example, when finalizing products obtained by selective laser melting technology.

\section{Conclusions}

- The possibility of changing the surface microgeometry and the cutting edge area on high-speed steel and hard alloy tools by laser ablation using a low-power nanosecond marking laser is shown. The technology is appropriate to use for the manufacture of small batches or single production.

- Rational modes at which more efficient, close to Gaussian energy distribution in the pulse of the laser marking system U-15 can be observed, and a more predictable profile for specifying the required microgeometry of the cutting edge is determined. The most uniform and smooth surface were obtained after laser treatment with the following parameters: a power of $60 \%$, a frequency of $10 \mathrm{kHz}$, a scanning speed of $200 \mathrm{~mm} / \mathrm{s}$. 
- When producing laser tracks, a number of specified production factors should be considered, such as power, scanning speed, pulse frequency rate, and the number of passes. For the cutting tools with wear-resistant coating (TiAl)N, the depth of the obtained tracks is greater than that of the uncoated instruments.

Acknowledgments. We gratefully acknowledge the financial support to this work by the Ministry of Education and Science of the Russian Federation, in the framework of the state task in the field of scientific activity of MSTU "STANKIN" (No. 11.1817.2017/4.6). The work is carried out on the equipment of the center of collective use.

\section{References}

[1] V.Y. Fominskii, S.N. Grigoriev, R.I. Romanov, V.N. Nevolin, Effect of the pulsed laser deposition conditions on the tribological properties of thin-film nanostructured coatings based on molybdenum diselenide and carbon, Tech. Phys. 57 (2012) 516-523

[2] A. Metel, S. Grigoriev, Yu. Melnik, Cutting tools nitriding in plasma produced by a fast neutral molecule, Jpn. J. Appl. Phys. 50 (2011) 08JG04

[3] O.V. Sobol, A.A. Andreev, S.N. Grigoriev, M.A. Volosova, V.F. Gorban, Vacuum-arc multilayer nanostructured $\mathrm{TiN} / \mathrm{Ti}$ coatings: structure, stress state, properties, Metal Sci. Heat Treat. 7 (2011) 28-33

[4] A.S. Vereschaka, A.A. Vereschaka, D.V. Sladkov, A.Y. Aksenenko, N.N. Sitnikov, Development and research of nanostructured multilayer composite coatings for tungsten-free carbides with the extended area of technological applications, Int. J. Adv. Manuf. Technol. 1 (2016) 9

[5] V.P. Tabakov, A.S. Vereschaka, Development of technological means for formation of multilayer composite coatings, providing increased wear resistance of carbide tools, for different machining conditions, Key Eng. Mater. 581 (2014) $55-61$

[6] S. Fedorov, M.H. Swe, Wear of carbide inserts with complex surface treatment when milling nickel alloy, Mech. Ind. 18 (2017) 710

[7] S.V. Fedorov, S.V. Aleshin, M.H. Swe, Comprehensive surface treatment of high speed steel tool, Mech. Ind. 18 (2017) 711

[8] C.J.C. Rodrigues, Mesogeometry of the cutting age, in: Cutting age preparation of precision cutting tools by applying micro-abrasive jet machining and brushing, Kassel University Press GmbH, Kassel, Germany

[9] F. Boud, L.F. Loo, P.K. Kinnell, The impact of plain waterjet machining on the surface integrity of aluminium 7475, Proc. CIRP 13 (2014) 382-386

[10] S.V. Fedorov, D. Weiss, M.H. Swe, Water-jet treatment as a way to prepare the surfaces of the solid alloy before applying the wear-resistant coating, Vestnik MGTU STANKIN 4 (2017) 48-51

[11] K.D. Bouzakis, G. Skordaris, N. Michailidis, A. Asimakopoulos, G. Erkens, Effect on PVD-coated cemented carbide inserts cutting performance if microblasting, Surf. Coat. Technol. 200 (2005) 12-132
[12] F.L. Chen, E. Siores, K. Patel, A.W. Momber, Minimising particle contamination at abrasive waterjet machined surfaces by a nozzle oscillation technique, Int. J. Mach. Tools Manuf. 42 (2002) 1385-1390

[13] S.B. Abusuilik, Pre-, intermediate, and post-treatment of hard coatings to improve their performance for forming and cutting tools, Surf. Coat. Technol. 284 (2015) 384-395

[14] A.S. Metel, S.N. Grigoriev, Yu.A. Melnik, V.V. Prudnikov, Glow discharge with electrostatic confinement of electrons in a chamber bombarded by fast electrons, Plasma Phys. Rep. 37 (2011) 628-637

[15] S.N. Grigoriev, A.S. Metel, S.V. Fedorov, Modification of the structure and properties of high-speed steel by combined vacuum-plasma treatment, Metal Sci. Heat Treat. 54 (2012) $8-12$

[16] S.N. Grigoriev, Yu.A. Melnik, A.S. Metel, Broad fast neutral molecule beam sources for industrial-scale beam-assisted deposition, Surf. Coat. Technol. 156 (2002) 44-49

[17] S.N. Grigoriev, Yu.A. Melnik, A.S. Metel, V.V. Panin, V.V. Prudnikov, A Compact vapor source of conductive target material sputtered by $3 \mathrm{keV}$ ions at $0.05 \mathrm{~Pa}$ pressure, Instrum. Exp. Tech. 52 (2009) 731-737

[18] S.V. Fedorov, S.N. Grigoriev, Tool surface microalloying by self-extending high-temperature synthesis, Mater. Sci. Forum 834 (2015) 21-28

[19] S.V. Fedorov, G.V. Oganyan, Special features of electronbeam alloying of replaceable polyhedral hard-alloy plates under a complex surface treatment, Metal Sci. Heat Treat. 9 (2016) 620-624

[20] J.M. Arryo, A.E. Diniz, M.S. Fernandes de Lima, Wear performance of laser precoating treated cemented carbide milling tools, Wear 268 (2010) 1329-1336

[21] B. Denkena, A. Kroedel, T. Grove, Influence of pulsed laser ablation on the surface integrity of PCBN cutting tool materials, Int. J. Adv. Manuf. Technol. 10 (2018) 1-12

[22] M.A. Volosova, S.N. Grigoriev, E.A. Ostrikov, Use of laser ablation for the formation of discontinuous (discrete) wearresistant coatings formed on hard carbide cutting tool by electron beam alloying and vacuum arc deposition, Mech. Ind. 17 (2016) 720

[23] R. Voss, M. Henerichs, G. Capricano, F. Kuster, K. Wegener, Post-coating treatment of cutting edge for drilling carbon fibre reinforced plastics, Proc. CIRP 46 (2016) 161-164

[24] S. Maegawa, S. Hayakawa, F. Itoigawa, T. Nakamura, Development of the novel tool for cutting of carbon-fibrereinforced plastics (positive use of abrasive wear at tool edge for the reduction in cutting force), Mech. Eng. J. 2 (2015) 6

[25] S. Marimuthu, A.M. Kamara, D. Whitehead, P. Matvienga, L. Li, Laser removal of TiN coatings from WC micro-tools and in-process monitoring, Optics Laser Technol. 42 (2010) $1233-1239$

[26] P. Mativenga, M. Rajemi, S. Marimutu, Establishing a basis for sustainable re-use of cutting tools through laser decoating, J. Mach. Eng. 10 (2010) 36-47

[27] S.V. Fedorov, A.V. Kabanov, E.A. Ostrikov, Technology of laser removal wear-resistant coatings from the surface of cutting tools made of hard alloys, Harden. Technol. Coat. 12 (2012) 40-43

[28] E. Uhlmann, S. Richarz, V. Mihotovic, Substrate pretreatment of cemented carbide using abrasive flow machining and laser beam ablation, Prod. Eng. 3 (2009) 81-86 
[29] B. Breidenstein, B. Denkena, K. Gey, Residual stress development in laser machined PVD-coated carbide cutting tools, Mater. Sci. Forum 9 (2013) 768-769

[30] L. Tiejun, L. Qihong, D. Jingxing, W. Yunrong, Z. Jun, L. Jingru, Z. Zhiming, S. Fanghong, Improved adhesion of diamond coating on cobalt-cemented tungsten carbide hard metal by using pulsed-UV-laser substrate surface pretreatment, Appl. Surf. Sci. 1-4 (2002) 102-119

[31] E. Cappelli, S. Orlando, F. Pinzari, A. Napoli, S. Kaciulis, WC-Co cutting tool surface modifications induced by pulsed laser treatment, Appl. Surf. Sci. 1-4 (1999) 376-382

[32] A. Miotello, R. Kelly, Laser-induced phase explosion: new physical problems when a condensed phase approaches the thermodynamic critical temperature, Appl. Phys. Mater. Sci. Process. 69 (1999) 67-73

[33] N.M. Bulgakova, A.V. Bulgakov, Pulsed laser ablation of solids: the transition from normal vaporization to phase explosion, Appl. Phys. Mater. Sci. Process. 73 (2001) 199-208

[34] B. Denkena, B. Breidenstein, Residual stress distribution in PVD-coated carbide cutting tools: the origin of cohesive damage, Tribol. Ind. 3 (2012) 158-165

[35] G.B.J. Cadot, D.A. Axinte, J. Billingham, Continuous trench, pulsed laser ablation for micro-machining applications, Int. J. Mach. Tools Manuf. 107 (2016) 8-20

[36] S. Long, D. Chantzis, A comparison of the DPSS UV laser ablation characteristic of 1024 and H10F WC, Opt. Laser Technol. 92 (2017) 101-108

[37] A.A. Vereschaka, S.N. Grigoriev, Study of cracking mechanisms in multi-layered composite nano-structured coatings, Wear 378-379 (2017) 43-57
[38] A. Nazarov, V. Vivier, D. Thierry, F. Vucko, B. Tribollet, Effect of mechanical stress on the properties of steel surfaces: scanning Kelvin probe and local electrochemical impedance study, J. Electrochem. Soc. 164 (2017) 66-74

[39] S. Qi, Z. Liu, Y. Hua, J. Zhao, W. Ly, A.U.H. Mohsan, Effects of cutting edge microgeometry on residual stress in orthogonal cutting of Inconel 718 by FEM, Materials 11 (2018) 1015

[40] I.A. Choudhury, N.L. See, M. Zukhairi, Machining with chamfered tools, J. Mater. Process. Technol. 170 (2005) 115-120

[41] N. Fang, Q. Wu, The effects of chamfered and honed tool edge geometry in machining of three aluminium alloys, Int. J. Mach. Tools Manuf. 45 (2005) 1178-1187

[42] B. Denkena, M. Reichstein, J. Brodehl, L.G. Lde, Surface preparation, coating and wear performance of geometrically defined cutting edges, in: 8th CIRP International Workshop on Modeling of Machining Operations, May 10-11, 2005

[43] B. Denkena, J. Koehler, M. Rehe, Influence of the honed cutting edge on tool wear and surface integrity in slot milling of 42CrNo4 steel, Procedia CIRP 1 (2012) 190-195

[44] T. Zhao, J.M. Zhou, V. Bushlya, J.E. Stähl, Effect of cutting edge radius on surface roughness and tool wear in hard turning of AISI 52100 steel, Int. J. Adv. Manuf. Technol. 91 (2017) 3611-3618

[45] A.S. Vaykhinde, U.B. Bhor, V.V. Sachhe, S.P. Valte, S.B. Deokar, Review of effect of tool nose radius on cutting force and surface roughness, Int. Res. J. Eng. Technol. 4 (2017) 699-703

[46] M. Shatla, C. Kerk, T. Altan, Process modelling in machining. Part II: validation and applications of the determined flow stress data, Int. J. Mach. Tools Manuf. 41 (2001) 1659-1680

Cite this article as: S.V. Fedorov, E.A. Ostrikov, E.S. Mustafaev, K. Hamdy, The formation of the cutting tool microgeometry by pulsed laser ablation, Mechanics \& Industry 19, 703 (2018) 